\title{
Thoracic pedicle screw placement: Free-hand technique
}

\author{
Yongjung J. Kim, Lawrence G. Lenke \\ One Barnes-Jewish Hospital Plaza, 11300 West Pavilion, St. Louis, Missouri - 63110, USA
}

Thoracic pedicle screws provide a number of advantages over other methods of spinal fixation in treating a variety of conditions including: better pull-out strength ${ }^{[1]}$ and greater control in the sagittal, coronal and rotational planes due to increased stability to axial, bending and rotational forces by three-column fixation, ${ }^{[2,3]}$ fewer vertebral motion segments arthrodesed, ${ }^{[4-9]}$ no or lessened need for postoperative bracing ${ }^{[10]}$ and secure fixation after laminectomy or incompetent posterior elements. ${ }^{[3,7,11]}$ In patients with spinal deformity, segmental pedicle fixation has demonstrated greater three-dimensional correction with decreased rates of curve progression and higher fusion rates, ${ }^{[5,8,10,12-15]}$ the ability to treat the rigid scoliosis between $70^{\circ}$ and $100^{\circ}$ curves without anterior release ${ }^{[15]}$ with smaller total hospital $\operatorname{cost}^{[16]}$ and direct apical vertebral derotation to enhance correction and potentially obviate the need for a thoracoplasty ${ }^{[17-19]}$ Also, the flexibility of multiple screw types allows easier connection to rods, especially in patients with deformity. ${ }^{[20]}$ Despite the potential benefits, many surgeons have avoided placing thoracic pedicle screws because of their concern on neurologic, vascular and visceral complications. ${ }^{[14,21-}$ ${ }^{26]}$ The purpose of this manuscript is to delineate the "Free-Hand" thoracic pedicle screw placement with respect to the pertinent anatomy, placement technique, confirmation of the accurate screw placement, salvage, reported complications and several methods to help avoid such complications.

\section{Surgical anatomy}

A thorough knowledge of thoracic vertebral and perivertebral anatomy including spinal cord, aorta and rib articulation is essential to understand and perform "Free-hand" pedicle screw placement technique. There are several consistent dimensions to the thoracic vertebrae for which there is general agreement in the literature despite the high interindividual variability. ${ }^{[3,7,11,27-42]}$

\section{Vertebral and perivertebral anatomy}

The transverse pedicle diameter is the critical anatomical variable on safe placement of the pedicle screw. Usually the lower thoracic spine (T10, T11 and T12) has the biggest pedicles varying from $6.3 \mathrm{~mm}$ to $7.8 \mathrm{~mm}$. The transverse pedicle diameter of the mid-thoracic pedicle from T4 to T9 has the smaller pedicles varying from 4.7 to $6.1 \mathrm{~mm}$. Usually the pedicle between $\mathrm{T} 4^{[3]}$ and $\mathrm{T} 6^{[30]}$ has the smallest pedicles while the largest is at $\mathrm{T} 12$. The T4 through T1 pedicles tend to become progressively larger (diameter between $5.6 \mathrm{~mm}$ and $7.9 \mathrm{~mm}$ ) when moving in a cephalad direction when analyzed in $\mathrm{CT}^{6}$ and cadaver ${ }^{[3,11,28,32,38]}$ studies. Several Asian studies ${ }^{[29,41,42]}$ demonstrated smaller transverse diameter in pedicle. In scoliotic spines, the concave pedicle is usually smaller than convex pedicle at the same vertebra. ${ }^{[13,40]}$

Misenheimer et $\mathrm{al}^{[6]}$ documented that the screw exceeds once the endosteal diameter of the pedicle, the pedicle will adapt in one of three ways: pedicle expansion, pedicle cutout by screw threads, or pedicle fracture. Pedicle changes occurred when greater than $80 \%$ of the outer cortical diameter was exceeded. In $72 \%$ of cases the fracture occurred laterally, with $28 \%$ medial occurrence. At all levels, the medial cortex is 2-3 times thicker than the lateral cortex. ${ }^{[30]}$ Sjöström et al ${ }^{[43]}$ noted that when the screw diameter exceeded $65 \%$ of the pedicles' outer diameter, $85 \%$ of the pedicles expanded. Recently Rinella et $\mathrm{al}^{[44]}$ demonstrated the viscoelastic expansion of the pediatric scoliotic pedicle of 9 -year-old boy, allowing $196 \%$ expansion before failure based upon CT scan measurement at the transverse internal diameter of the pedicle isthmus of one level. This data was equivalent to the $111 \%$ expansion before failure based upon CT scan measurement at the transverse external transverse diameter of the pedicle isthmus.

The transverse angle of the pedicle demonstrated a consistent decrease from 30 degrees convergent at $\mathrm{T} 1$ to neutral or 5 degrees divergent at T12. ${ }^{[38]}$ In the proximal thoracic spine, the transverse pedicle angle decreased sequentially to 13.9 degrees in the fourth thoracic vertebra. ${ }^{[3]}$ The transverse angle of the pedicle between $\mathrm{T} 4$ and $\mathrm{T} 9$ is quite similar between 13.9 degrees in the fourth thoracic vertebra to 7 degrees in the ninth thoracic vertebra. ${ }^{[3]}$ The pedicle axis of the lower thoracic spine (T10, $\mathrm{T} 11$ and $\mathrm{T} 12)$ became neutral to slightly divergent because the

\footnotetext{
Lawrence G. Lenke

Co-chief Adult/Pediatric Spinal Surgery One Barnes-Jewish Hospital Plaza · 11300 West Pavilion St. Louis, Missouri, USA
}

E-mail: lenkel@msnotes.wustl.edu 
location of the rib head sequentially moved backward toward the base of the pedicle at T11 and T12. So even the lower thoracic pedicles provide the firm purchase of the pedicle screw from a lateral starting point and 10-15 degrees convergent angle. ${ }^{[46]}$ (Figure 1)

Adequate pedicle screw length according to chord length is very important to prevent vascular or visceral complications. Chord length remains relatively constant at 39-47 mm (39 mm at T6 and $47 \mathrm{~mm}$ at T12). ${ }^{[3]}$ Another important landmark for safe screw placement is the distance from the dorsal lamina to the isthmus of the pedicle. Our cadaver study demonstrated that the average distance between the dorsal lamina to the isthmus of the pedicle was $12.2 \mathrm{~mm}$ (range, 11-13 $\mathrm{mm}$ ). ${ }^{[4]}$

The shape of the pedicle is quite variable. An oval shape occurs most consistently in the upper thoracic spine and the cephalocaudad and mediolateral dimensions are almost the same. Throughout the remainder of the thoracic spine, the pedicles have been described to have a teardrop or kidney-bean shape. ${ }^{[30,48]}$ Rinella et $\mathrm{al}^{[44]}$ demonstrated the shape change toward oval pedicle according to the pedicle expansion.

The nerve roots increase in size from approximately $3 \mathrm{~mm}$ at $\mathrm{T} 1$ to $4 \mathrm{~mm}$ at T12. The spinal cord directly abuts the medial aspect of the pedicle in a cadaver study ${ }^{[33,34]}$ In a similar study, dural sac is within $0.0-0.7 \mathrm{~mm}$ of the medial pedicle in the thoracic spine. ${ }^{[7]}$ Vaccaro et al. assessed the proximity of important neurovascular structures using a cadaver specimen. ${ }^{[49]}$ Superior intercostals vessels (T4-T5), esophagus (T4-T9), azygous vein (T5-T11), inferior vena cava (T11-T12) and the thoracic duct (T4-T12) are endangered when screws are placed on the right side of the body. The esophagus (T4-T9) and aorta (T5-T12) may be damaged by screws placed on the left sided pedicles. When screws are placed laterally, the lung, segmental vessels and sympathetic chain are in jeopardy on both sides. The aorta is endangered on the left (T5-T10) with laterally placed screws and the azygous vein on the right (T5T11).

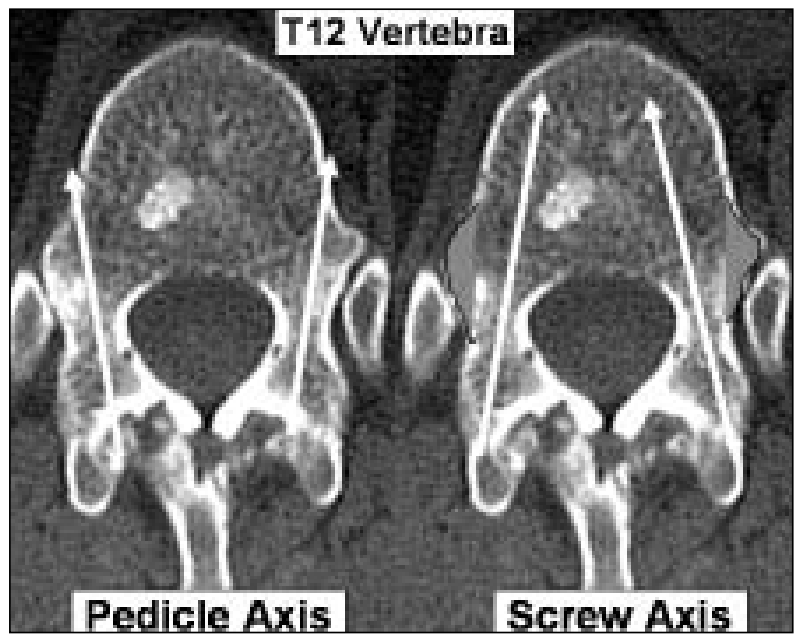

Figure 1: Lower thoracic pedicles provide the firm purchase of the pedicle screw from a lateral starting point and 10-15 degrees convergent angle

\section{Surgical technique \\ "Free Hand" pedicle screw placement ${ }^{[50]}$}

Our "Free Hand" technique is equivalent for lumbar and thoracic pedicle screws placement using anatomical landmark and a specially designed gearshift based on three important principles: 1. starting point; 2. trajectory; 3. "intraosseous feel" of the pathway down the pedicle into the body. After the initial exposure, each step is repeated sequentially at each level to be instrumented. Complications can be minimized by using the free-hand anatomic technique described in this chapter with appropriate sensory, motor and EMG neurophysiologic monitoring technique.

1. Exposure: A meticulous exposure of the posterior elements to be fused is critical to successful screw insertion. The dissection should be limited to only the fusion levels in order to limit softtissue destruction and reduce the potential for.junctional kyphosis or transition syndromes. Usually proximal junctional dissection is a little difficult. We have to place pedicle screws at the most proximal and distal vertebrae without disrupting the facet capsules, supraspinous and interspinous ligaments and ligamentum flavum either proximally and distally. One must see out to the tips of the transverse processes, superior articular facet and spinous process/ laminar slope bilaterally.

2. Facetectomy: The inferior $3-5 \mathrm{~mm}$ of the inferior facet is osteotomized and articular cartilage on the dorsal side of the superior facet is completely removed except for the lowest instrumented vertebra. The base of the superior articular process is very important landmark to the ventral pedicle. (Figure 2)

3. The Starting Point: The starting point for each thoracic screw is slightly variable. Usually the supine or push-prone preoperative film is very illustrative to find the ideal starting point. It is also biomechanically beneficial to place each screw in a position parallel to the superior endplate in the thoracic spine (straight-forward trajectory technique by Lehman et al. ${ }^{[51]}$ ) In general, visualize the starting point based upon as much as anatomical information as possible and always start from the neutrally rotated and distal vertebra. When starting distal at $\mathrm{T} 12$, there is a trend towards a more medial and cephalad pedicle starting point on the posterior elements as one proceeds toward the apical midthoracic region (T7-T8). Proximal to this, the starting point tends to move more lateral and caudad as one proceeds more proximal to the T1 level. It is advantageous to note these trends when placing a screw at each level in succession, working from distal to proximal in the thoracic spine and to making fine adjustments to the trajectory of the previous level's screw or contralateral screw. It is also important to have smooth transitions between each screw in order to more easily place the rod. [Figure 3]

4. Dorsal Cortical Burring: A $3.5 \mathrm{~mm}$ acorn-tipped burr is utilized to create a posterior cortical breach, approximately $5 \mathrm{~mm}$ in depth. The pedicle "blush" may be visualized suggesting entrance into the cancellous bone of the pedicle. This may not be seen in smaller, apical concave pedicles because of very limited intrapedicular cancellous bone. In this situation, the tip of a probe may be required to find this in a funnel-like technique. The ventral lamina (roof of the spinal canal) can be palpated by percussion 


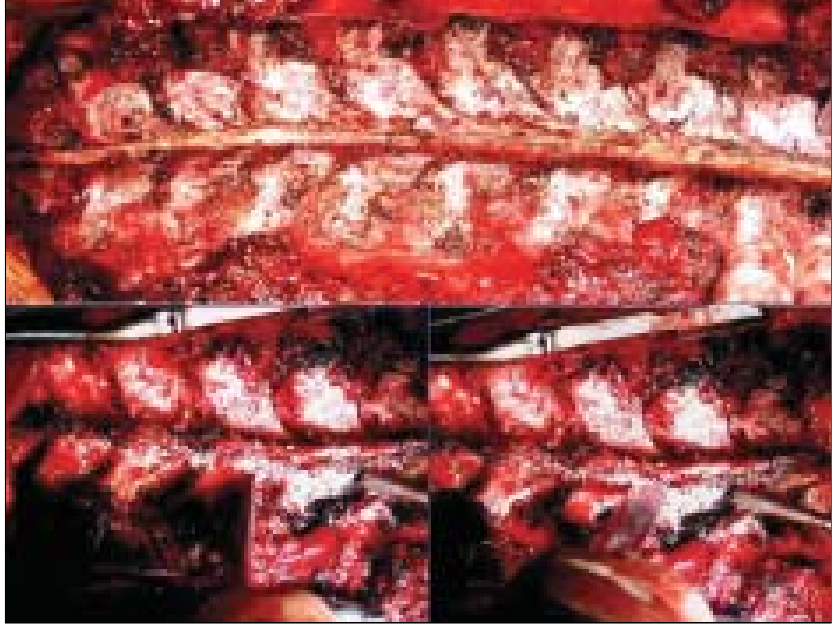

Figure 2: The base of the superior articular process is very important landmark to the ventral pedicle
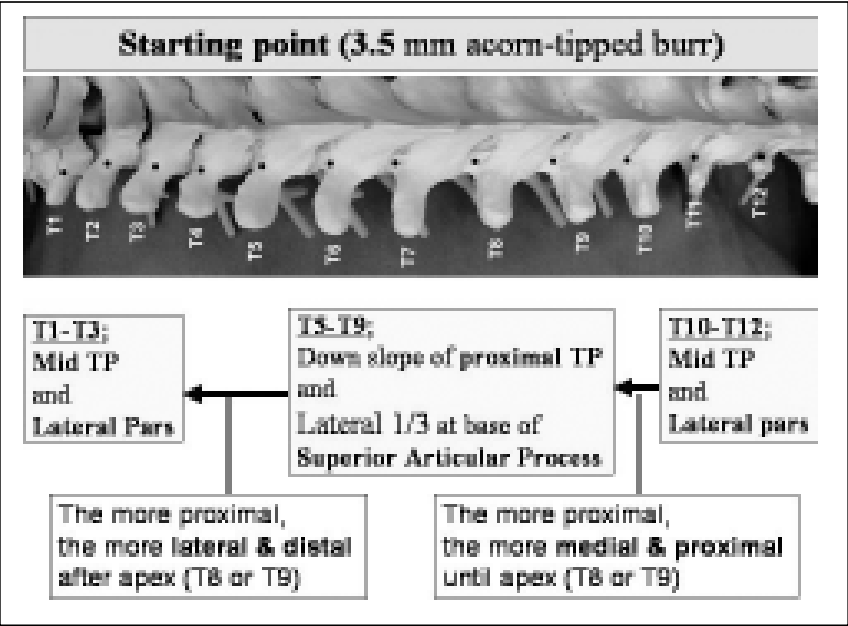

Figure 3: Starting points at different levels of thoracic spine

and ventral lamina invagination can be avoided.

5. The Gearshift Probing: With appropriate amount of ventral pressure, the thoracic gearshift is placed in the base of the pedicle searching for a cancellous "soft spot" indicating entrance to the pedicle. This thoracic gearshift has $2 \mathrm{~mm}$ blunt-tipped, slight curvature throughout $35 \mathrm{~mm}$ tip with round to rectangular edge and makes a pathway with a total diameter of approximately $4 \mathrm{~mm}$. The gearshift is initially pointed lateral as a safety measure to avoid medial wall perforation. One can identify the ventral lamina by percussion if necessary and avoid medial pedicle penetration. After inserting the tip approximately $15-20 \mathrm{~mm}$ (the length of the pedicle), the gearshift is removed and the tip turned to face medial. Before advancing the pedicle finder, place the tip carefully to the base of the prior hole. This technique is extremely useful as vertebral rotation may be deceiving. We prefer the straight-forward trajectory technique due to the $39 \%$ increase in maximum insertion torque and a $27 \%$ increase in pull-out strength compared to the anatomic technique. ${ }^{[51]}$ The path down the pedicle is then continued medial into the body with an ultimate depth averaging $40-45 \mathrm{~mm}$ for the lower thoracic region, $35-40 \mathrm{~mm}$ in

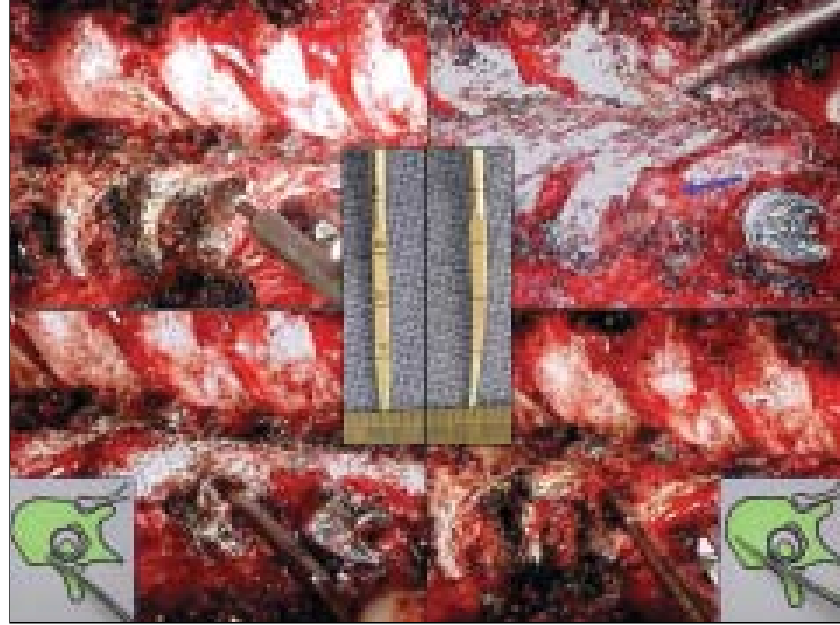

Figure 4: The thoracic gear-shift

the mid thoracic region and 30-35 $\mathrm{mm}$ for the proximal thoracic region in adolescents and most adults. Rotate the finder 180 degrees to make room for the screw after advancing the finder to the approximate length of the desired screw. Make sure you feel bone the entire length of the pedicle. The surgeon must pay strict attention to the axial and sagittal position of the vertebrae in space to position the probe down the pedicle shaft appropriately. In addition, probing of the pedicle with the thoracic gearshift should proceed in a smooth and consistent manner with a snug. feel because of the small size of the thoracic pedicles. Any sudden advancement of the gearshift suggests penetration into soft tissue and thus a pedicle wall violation or vertebral body violation. These should be investigated immediately in order to possibly salvage the pedicle and avoid complications. (Figure 4)

Our CT scan study demonstrated that the average transverse angle of the acceptable screws was $15.3^{\circ}$. That of the laterally violated screws was $10.6^{\circ}$ and that of medially violated screws was $23^{\circ}$. The difference of the transverse angle was more significant in the thoracic spine. ${ }^{[46]}$ Often the endosteal diameter of the pedicle is quite small, so one must allow the finder to "fall" into the pedicle. It is important not to extend deep anterior or lateral to the body in the thoracic spine and the thoracic gearshift is calibrated for that purpose. The anterior and lateral vertebral body cortices are not very strong and are easily penetrated by the gearshift tip. Approximately $60 \%$ of the strength of the screw comes from the pedicle itself, with an additional $20 \%$ added in the posterior half of the vertebral body. ${ }^{[52]}$ There is not a significant increase in strength in the anterior vertebral body unless the anterior cortex is tapped. This is not recommended in any level besides the sacrum because of the risk of damage to the vascular and visceral structures. Therefore, it is not always necessary to place the screws beyond the posterior $50-70 \%$ of the vertebral body.

Normal thoracic pedicle screw diameters will vary between $6.5 \mathrm{~mm}$ for the lower thoracic region, down to $5.0 \mathrm{~mm}$ in the concave apex of a scoliosis deformity in the mid-thoracic region, or the proximal thoracic region. We decide the screw diameter based 
upon preoperative assessment as well as how the pedicle "feels" with the pedicle finder. Pedicle diameter transitions occur gradually, so segmental fixation allows one to note the fine variations between levels, with the goal of maximum fit and fill of the screw within the pedicle.

6. Palpation: Once the pedicle seeker is removed, the tract is visualized to make sure that only blood is coming out and not CSF. One must notice the amount of blood extruding from the pedicle hole, as excessive bleeding may indicate epidural bleeding secondary to a medial wall perforation. Pack the pedicle tract with bone wax if clear CSF is observed and consider revise the trajectory more lateral. Next, a flexible ball-tipped pedicle sounding or palpating device is utilized to palpate five distinct bony borders: a floor and four walls (medial, lateral, superior and inferior). Pay special attention to the junction of the middle and upper portions of the tract (the first $10-15 \mathrm{~mm}$ of the tract) as this is the region of the pedicle where the spinal canal and the pedicle isthmus are located. At this point, if a soft tissue breach is palpated, there may be an opportunity to redirect the screw into an appropriate position into the pedicle so that complete intraosseous borders can be obtained. If any wall besides the medial has been breached, the pedicle may be salvageable. Otherwise, place the bone wax in the pedicle hole to limit the bleeding and re-angle the pedicle finder with a more appropriate trajectory.

7. Pedicle length measurement: With the sounder in the base of the anticipated pedicle tract after confirming five intraosseous borders, mark the length of the tract with a hemostat and measure it. If the tract appears too shallow, consider replacing the gear shift and advancing to the appropriate length.

8. Tapping: The pedicle tract is undertapped with a $1.0 \mathrm{~mm}$ less diameter tap than the intended screw (e.g. $4.5 \mathrm{~mm}$ tap for a $5.5 \mathrm{~mm}$ diameter screw). Undertapping the thoracic pedicle by $1 \mathrm{~mm}$ increases maximal insertional torque by $47 \%$ when compared with undertapping by $0.5 \mathrm{~mm}$ and by $93 \%$ when compared with tapping line-to-line. ${ }^{[53]}$ If there is difficulty passing the tap, use the next smaller tap and re-tap the pedicle. If the pedicle is quite small or when more than one pass has to be made into a pedicle with the thoracic gearshift, then a K-wire is placed down the pedicle tunnel into the body and cannulated tapping can occur over that. It is mandatory that a bony floor exists when using a K-wire so as not to advance the K-wire beyond the anterior or lateral cortex. If there is any question whether the anterior wall is intact, never use a K-wire as cardiac tamponade due to K-wire induced trauma to a coronary artery has been reported. ${ }^{[22]}$ Tapping is very necessary to allow for slow and safe pedicle expansion up to $200 \%$ of the internal diameter of the pedicle without causing a significant decrease in the screw holding power because of plasticity of the pedicular cortex in pediatric patients. ${ }^{[4]}$ We have determined the screw diameter using the internal diameter of the neutrally rotated spine as a reference diameter and the tightness of the tap. Now we can insert $5.0 \mathrm{~mm}$ screw if the internal diameter of the pedicle is more than $2.5 \mathrm{~mm}$.

9. Second palpation: Following tapping the pedicle tract is palpated again to make sure that the five osseous borders are intact. Tapping can create the bony ridges to aid in second palpation. This second palpation will often allow palpation of distinct bony ridges confirming intraosseous position and remeasure the tract length with a hemostat. Compare this measurement directly adjacent to the screw to be placed to ensure appropriate screw length (Figure 5).

10. Screw placement: Place the screw slowly down the pedicle into the body in the same alignment to confirm it is threaded properly and allow for viscoelastic expansion. It is advantageous to have a variety of pedicle diameters and lengths available. We have used screws with diameters between $4.5 \mathrm{~mm}$ to $7.0 \mathrm{~mm}$ in $0.5 \mathrm{~mm}$ increments and lengths ranging from $25 \mathrm{~mm}$ for the smaller diameter screws up to $55 \mathrm{~mm}$ for the larger diameter screws. Typical screws range from $45 \mathrm{~mm}$ in length in the distal thoracic spine to $30-35 \mathrm{~mm}$ in the proximal thoracic spine For the most part, we use fixed-angle screws; however, multiaxial screws may be helpful in the hyperkyphotic thoracic spine and in the entire lumbar spine. Monoaxial pedicle screws provide superior corrective capacity (rotation) compared to the multiaxial screw. ${ }^{[54]}$ Screws are inserted on every segment on the correction sides such as concave side of the idiopathic normo- and hypokyphotic scoliosis and convex side of the hyperkyphotic idiopathic scoliosis. For supportive side we have inserted screws every third or fourth level after inserting two lower most screws for pedicle screw translational technique. In kyphosis, congenital scoliosis and bilateral apical vertebral rotational technique, more screws have been inserted to increase the rigidity of the instrumentation.

\section{Confirmation of accurate screw placement}

1. Confirmation by palpation: We recommend minimum two palpations prior to and after tapping. This is an absolutely critical step, whereby inadvertent deep (anterior), medial, lateral or more rare superior and inferior pedicle breaches can be identified. However, an observer's ability to accurately detect the presence or absence of a pedicle tract violation and breach location, if present, is dependent on the surgeon's level of training. ${ }^{[55]}$

2. Confirmation by intraoperative $\mathrm{AP}$ and lateral plain radiographs: When assessing the pedicles, the most common method is AP and lateral radiographs. These should be reviewed carefully in all cases. Three plain radiographic criteria using PA intraoperative plain radiograph were used to judge the accuracy of screw position: 1) Violation of the harmonious segmental change of the tips of the inserted screws with reference to the vertebral body rotation (medial or lateral out); 2) no crossing of the medial pedicle wall by the pedicle screw inserted (lateral out); and 3) violation of the imaginary midline of the vertebral body using the posterior upper spinolaminar junction in the plain PA x-ray by the absolute position of the tip of the inserted pedicular screw after minor screw tip position adjustment according to the lateral X-ray (medial out). The position of the screw tip in coronal plane radiograph should be somewhere between medial wall of the pedicle and imaginary midline of the vertebral body if the internal diameter of the pedicle is $<7 \mathrm{~mm}$. On the lateral x-ray, the screws should be parallel to the superior endplates and not extending past the 
anterior border of the vertebral body. ${ }^{[56]}$

In cases with a scoliotic with rotational component, the oblique nature of the image may make pedicle assessment difficult. Kim et $\mathrm{al}^{[47]}$ suggested anatomical landmark on a scoliotic spine. One can anticipate the distance from the anterior mid-vertebral body to the contralateral vertebral body line using the distance from the posterior spinolaminar junction to the ipsilateral lateral vertebral body line. The average differences between the distance from the posterior upper spinolaminar junction to ipsilateral lateral vertebral body line ( $\mathrm{X}$ in the figure) and that from the anterior tip of the K-wire to the other lateral vertebral body line ( $\mathrm{Y}$ in the figure) was $3 \mathrm{~mm}$ (average $2-4 \mathrm{~mm}$ ). Midvertebral body line from the posterior spinolaminarjunction to anterior mid-vertebral body can be useful landmark to place safe and reliable pedicle screw during scoliosis operation (Figure 6).

The coronal plane radiograph is evaluated for the harmonious position of all screws especially when any rotational deformity exists such as in scoliosis. The screw length on the lateral x-ray is useful to adjust the screw tip position on $\mathrm{PA}$ radiograph. After adjustment of the screw tip position, we can apply three radiographic criteria mentioned above to rule out significantly violated screws (Figure 7).

3. Confirmation by intraoperative $\mathrm{AP}$ and lateral fluoroscopy:

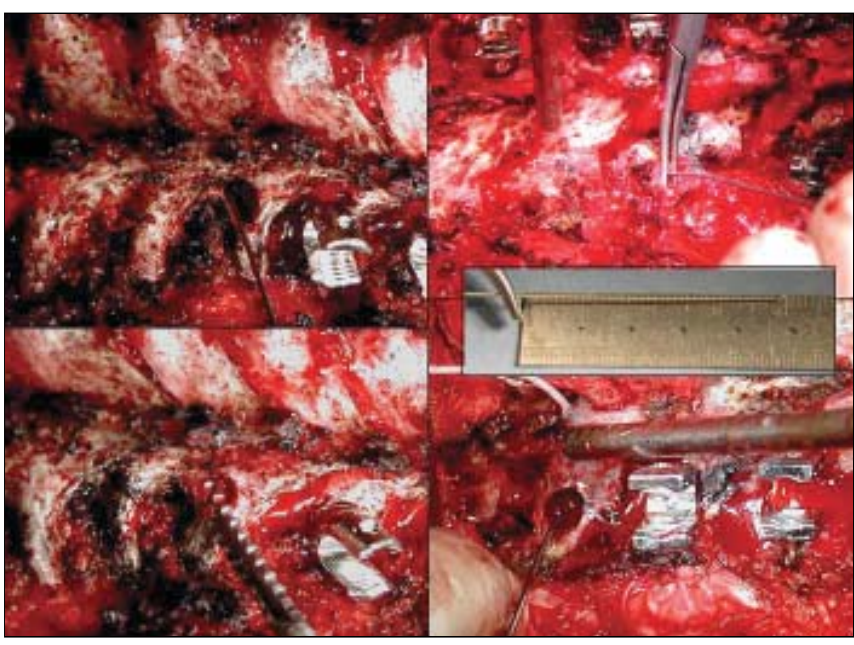

Figure 5: Measuring the right screw length

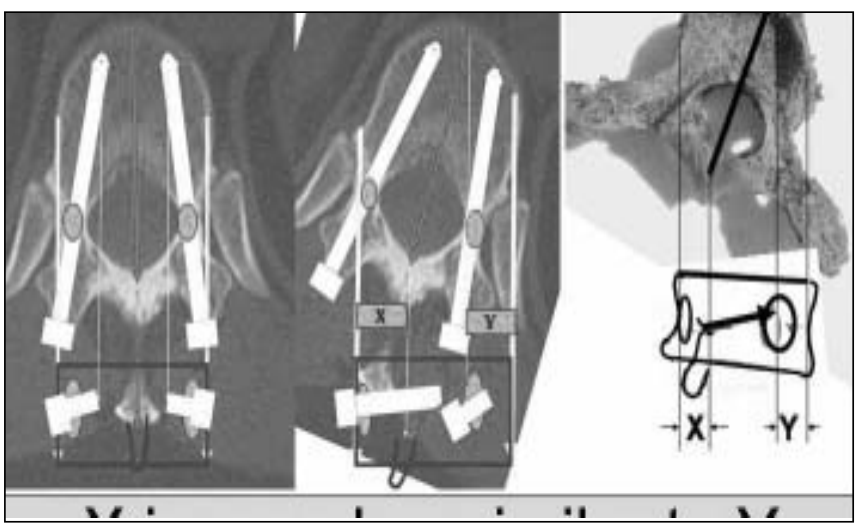

Figure 6: Calculations for a safe and reliable pedicle screw placement
After placing fluoroscopy in true AP and lateral, we can apply the same three radiographic criteria mentioned previously. This is relatively more accurate verification method than plain radiographic technique on rotated spine. However, more radiation exposure and time may be drawbacks.

4. Confirmation of Intraosseous Screw by triggered EMG: EMG stimulations are performed with real time monitoring of the thoracic nerve root recording from the rectus abdominus muscles for screws placed from T6 to T12. EMG from intercostal muscles was not reliable. ${ }^{[57]}$ So we do not use EMG confirmation for T1 to T6 pedicle screws. We re-check and re-palpate the thoracic pedicle tract with a ball-tipped sounder for EMG threshold level less than $6 \mathrm{~mA}$ or less than $65 \%$ of the mean of all other T6-T12 screws in that patient to confirm intraosseous placement. ${ }^{[58]}$ These EMG results should be taken along in context with results from pedicle palpation, screw positioning on radiographs and overall assessment of how each screw feels during placement throughout the thoracic and lumbar spine. ${ }^{[59-61]}$

5. Confirmation of Postoperative CT Scanning: This is not helpful to define intraoperative screw placement. However, it is very good idea to check postoperative CT scans early on and confirm accurate screw placement. Also, we strongly recommend early CT scan when the pedicle screw is in doubt. For a better CT scan image, tilting of the Gantry angle bisecting both pedicle screws is very helpful. Thin slice CT scan (1mm) is more informative because of volume averaging effect.

\section{Salvage procedure}

After confirming a pedicle wall breach, it is possible to create new wall including the medial side. For better purchase, we use a different direction or the anatomical trajectory at first. The anatomical trajectory achieved $62 \%$ of the maximal insertional torque during salvage of a failed/violated pedicle and provides adequate fixation in a salvage situation. ${ }^{[62]}$ After making new trajectory, we utilize a K-wire to maintain the accurate tract with cannulated taps. Extrapedicular placement of the pedicle screw is also possible. The starting point has to be moved out far lateral on

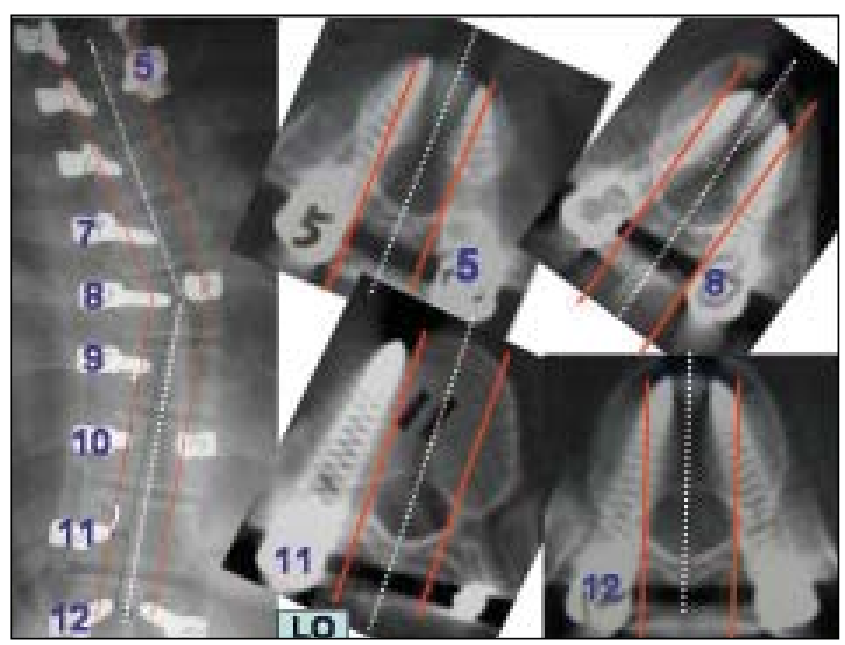

Figure 7: Evaluation of coronal plane radiograph in the presence of rotational deformity 
transverse process and more medial angulation is necessary. Although this is weaker purchase compared with intraosseous pedicle screw, this is still much stronger than hooks. After these salvage procedures, hooks such as upgoing pedicle, downgoing infralaminar, downgoing transverse process and combination of these techniques along with sublaminar wiring technique are also possible. ${ }^{[50]}$

\section{Results}

Greater than 8000 thoracic pedicle screws ( 850 patients, 2 to 85-years-old) were placed in our institution now. There were no visceral and vascular complications. There were two screws removed causing radiculopathy at T1 and T12 level. We have encountered six compression fractures without neurologic deficits at the cephalad end of spinal construct placed for spinal deformity (two at T3, three at T11 and one at T12. One in AIS and five adult deformities). Our CT scan study revealed that sixty-five among 789 pedicle screws ( $8 \%$ ) demonstrated significant pedicle wall violations ( 15 screws with medial wall violation vs. 50 screws with lateral wall violation) without any neurologic, vascular, or visceral complications. ${ }^{[46]}$ The total number of the periapical screws inserted into concave pedicle increased significantly from 87 among 124 (70\%) in the first 2-year group to 134 among 148 concave periapical pedicles $(91 \%)$ in second 2 -year group. The learning curve for free hand pedicle screw placement in AIS is substantial. ${ }^{[63]}$

\section{Reported complications CT scan rate of screw malposition}

For thoracic pedicle screws used in the treatment of spinal deformities, the incidence of screw misplacement ranges from $3 \%$ to $44.2 \%$. The wide variations in the rate of the screw misplacement may be attributed to the different method of evaluating the position of the pedicle screws. Gertzbein and Robinsons ${ }^{[64]}$ reported $15 \%$ of 71 screws inserted using intraoperative fluoroscopy into a non-deformed thoracic spine

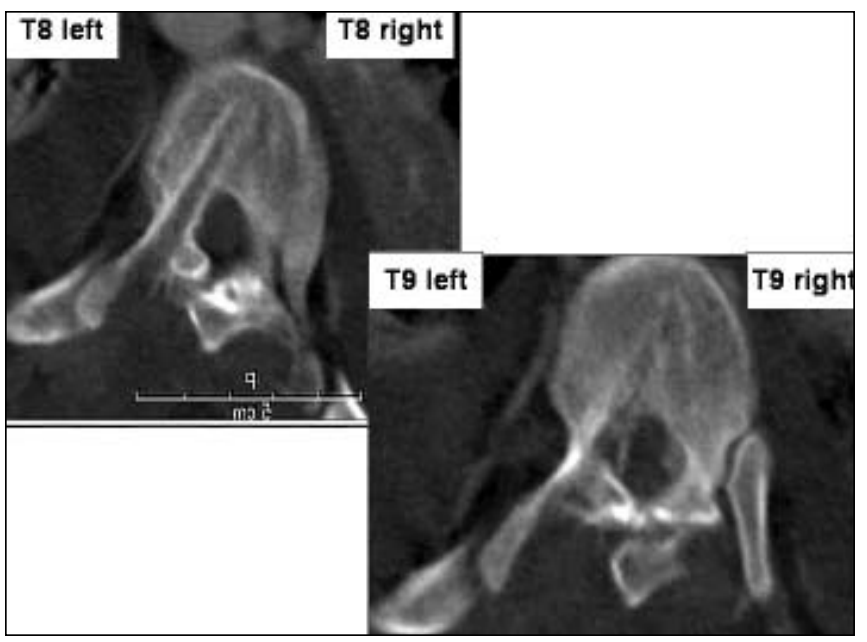

Figure 8: Breach of pedicle walls at T8 and T9 between T 8 and T12 had penetrated the medial pedicle cortex by 2.1-8.0 $\mathrm{mm}$ into the spinal canal. Only two patients developed neurologic complaints, which resolved spontaneously after 6 months without screw removal. Linjenqvist et $\mathrm{al}^{[13]}$ reported that ten screws $(8.3 \%)$ out of 126 screws in idiopathic scoliosis violated the medial pedicle wall by an average of $1.5 \mathrm{~mm}$ and a maximum of $3 \mathrm{~mm}$. There were no neurologic complications in any cases. Belmont et al ${ }^{[65]}$ reported only two screws were out between 2 and $4 \mathrm{~mm}$ among 279 thoracic pedicle screws which were inserted using intraoperative fluoroscopy which were confirmed by computed axial tomography. Youkilis et $\mathrm{al}^{[66]}$ reported 19 (8.5\%) cortical violations, which included eight $(3.6 \%)$ violations more than 2 mm out of 224 image-guided thoracic pedicle screws confirmed by postoperative CAT scan. Transgression of the medial thoracic pedicle wall up to $4 \mathrm{~mm}$ is not necessarily associated with neurologic complications because medial breach up to $4 \mathrm{~mm}$ by a thoracic pedicle screw causes similar loss of spinal canal cross-sectional area as 1 or 2 intracanalicular hooks. ${ }^{[45]}$

\section{Neurologic complications}

Papin et al ${ }^{[23]}$ reported an unusual presentation of spinal cord compression from pedicle screws consisting of persistent abdominal pain, mild lower extremity weakness, tremor at rest, thermoalgic discrimination loss and unexplained imbalance. The symptoms resolved after the medially placed thoracic screws were removed. Suk et al ${ }^{[14]}$ reported one neurologic injury causing transient paraparesis due to a medial pedicle perforation causing a delayed epidural hematoma. The paresis occurred in a patient with neurofibromatosis and resolved within 3 weeks after screw removal, hematoma evacuation and decompression. Alanay et $\mathrm{al}^{[24]}$ reported late spinal cord compression caused by pulled-out pedicle screws inserted into T2. Kasten et al ${ }^{[26]}$ reported two "shear-type" fractures at T6 and T10 thoracic pedicle within 6 weeks postoperative with incomplete paraplegia. The screwinstrumented model showed that stresses were concentrated at the medial part of the pedicle, inside the medullary cavity according to the Gayet et al. ${ }^{[67]}$ Although there are no case reports regarding paraplegia during thoracic pedicle screw insertion, we have heard anecdotal paraplegia cases all over the world through personal communications. We strongly recommend repetitive and compulsive steps to place screws and confirm intraosseous placement as much as humanly possible.

This patient had met SSEP warning criteria during pedicle screw insertion. A Postoperative CT scan done after screw removal demonstrated transgression of the left concave medial pedicle wall at T8, fracture and displacement of the left concave medial pedicle wall and bony shadow medial to the right convex medial wall at T9 pedicle. Postoperative neurologic examination demonstrated complete paraplegia below T9 level and the patient started on mega dose steroid therapy (Figure 8).

\section{Vascular complications}

Heini et al ${ }^{[22]}$ described a case of fatal cardiac tamponade that was due to a prick injury of the right coronary artery by a Kirschner 
wire. The injury was confirmed by autopsy after the patient died 12 days after surgery. Suk et al ${ }^{[14]}$ described a case of an overpenetrated screw causing irritation of the thoracic aorta resulting in severe chest pain. Recently Minor et al ${ }^{[25]}$ reported endovascular treatment of an iatrogenic aortic injury by misplaced thoracic pedicle screw at $\mathrm{T} 5$.

\section{Conclusion}

Thoracic pedicle screw instrumentation allows various advantages. In spite of many advantages, neurologic, visceral, vascular and other complications related to pedicle screw placement or constructs are possible. The free hand technique of thoracic pedicle screw placement performed in a step-wise, consistent and compulsive manner is an accurate, reliable and safe method of insertion to treat a variety of spinal disorders, including spinal deformity.

\section{References}

1. Liljenqvist U, Hackenberg L, Link T, Halm H. Pullout strength of pedicle screws versus pedicle and laminar hooks in the thoracic spine. Acta Orthop Belg. 2001;67:157-63.

2. Krag MH, Weaver DL, Beynnon BD, Haugh LD. Morphometry of the thoracic and lumbar spine related to transpedicular screw placement for surgical spinal fixation. Spine 1988;13:1988.

3. Vacearo AR, Rizzolo S.J, Allardyce T.J, Ramsey M, Salvo J, Balderston RA, et al. Placement of pedicle screws in the thoracic spine. Part I: Morphometric analysis of the thoracic vertebrae. J Bone Joint Surg Am 1995;77:1193-9.

4. Krag MH, Beynnon BD, Pope MH, Frymover JW, Haugh LD, Weaver DL. An internal fixator for posterior application to short segments of the thoracic, lumbar, or lumbosacral spine. Design and testing. Clin Orthop 1986;203:75-98.

5. Liljenqvist U, Lepsien U, Hackenberg L, Niemeyer T, Halm H. Comparative analysis of pedicle screw and hook instrumentation in posterior correction and fusion of idiopathic thoracic scoliosis. Eur Spine J 2002;11:336-43.

6. Misenhimer GR, Peek RD, Wiltse LL, Rothman SL, Widell EH Jr. Anatomic analysis of pedicle cortical and cancellous diameter as related to screw size. Spine $1989 ; 14: 367-72$

7. Ugur HC, Attar A, Uz A, Tekdemir I, Egemen N, Genc Y. Thoracic pedicle: surgical anatomic evaluation and relations. J Spinal Disord 2001;14:39-45.

8. Kim YJ, Lenke LG, Bridwell KH, et al. Comparative analysis of pedicle serew versus hook instrumentation in posterior spinal fusion of adolescent idiopathic scoliosis: A matched cohort analysis. Spine SRS Issue 2004;29S:2040-8.

9. Kim Y.J, Lenke LG, Bridwell KH, Kim J, Cho SK. Selection of the lowest instrumented vertebra in thoracic adolescent idiopathic scoliosis (Lenke type 1 and 2 ) following segmental posterior spinal fusion, Poster presentation by North America Spine Society annual meeting: Chicago; October 2004.

10. Suk SI, Lee CK, Kim WJ, Chung Y.J, Park YB. Segmental pedicle screw fixation in the treatment of thoracic idiopathic scoliosis. Spine 1995;20:1399-405.

11. Cinotti G, Gumina S, Ripani M, Postacchini F. Pedicle instrumentation in the thoracic spine. A morphometric and cadaveric study for placement of screws. Spine $1999 ; 24: 114-9$

12. Hamill CL, Lenke LG, Bridwell KH, Chapman MP, Blanke KM, Baldus CR. The use of pedicle screw fixation to improve correction in the lumbar spine of patients with idiopathic scoliosis. Is it warranted? Spine 1996;21:1241-9.

13. Liljenqvist UR, Halm HF, Link TM. Pedicle screw instrumentation of the thoracic spine in idiopathic scoliosis. Spine 1997;22:2239-45.

14. Suk SI, Kim WJ, Lee SM, Kim JH, Chung ER. Thoracic pedicle screw fixation in spinal deformities: are they really safe? Spine 2001;26:2049-57.

15. Luhmann SJ, Lenke LG, Kim YJ, Bridwell KH, Schootman M. Thoracic adolescent idiopathic scoliosis curves between 70 and 100 degrees: Is anterior release necessary? Spine, SRS Issue 2005 (Accepted December 2004).

16. Luhmann S.J, Lenke LG, Kim Y.J, Bridwell KH, Schootman M. Cost analysis of circumferential fusion versus posterior fusion-only with thoracic pedicle screw constructs of 70-100 degree idiopathic thoracic curves. SRS 2005 (Submitted).

17. Kim Y.J, Lenke LG, Bridwell KH. Prospective evaluation of pulmonary function in adolescent idiopathic scoliosis relative to the surgical approach: Minimum 5 vear follow-up (Accepted in JB.JS Am. 2004).

18. Lee SM, Suk SI, Chung ER. Direct vertebral rotation: a new technique of threedimensional deformity correction with segmental pedicle screw fixation in adolescent idiopathic scoliosis. Spine 2004;29:343-9.

19. Kim YJ, Lenke LG, Bridwell KH, Cheh G. Bilateral apical vertebral derotational pedicle screw instrumentation in the posterior spinal fusion of adolescent idiopathic scoliosis: Comparison with pedicle screw translational techniques. Podium presentation, International Meeting on Advanced Spine Technology Annual Meeting: Bermuda; 2004.

20. Brown CA, Lenke LG, Bridwell KH, Geideman WM, Hasan SA, Blanke KM. Complications of pediatric thoracolumbar and lumbar pedicle screws. Spine $1998 ; 23: 1566-71$.

21. Levine DS, Dugas JR, Tarantino S.J, Boachie-Adjei O. Chance fracture after pedicle screw fixation. A case report. Spine 1998;23:382-5.

22. Heini P, Scholl E, Wyler D, Eggli S. Fatal cardiac tamponade associated with posterior spinal instrumentation. A case report. Spine 1998;23:2226-30.

23. Papin P, Arlet V, Marchesi D, Rosenblatt B, Aebi M. Unusual presentation of spinal cord compression related to misplaced pedicle screws in thoracic scoliosis. Eur Spine J 1999;8:156-9.

24. Alanay A, Cil A, Acaroglu E, Caglar O, Akgun R, Marangoz S, et al. Late spinal cord compression caused by pulled-out thoracic pedicle screws: A case report. Spine $2003 ; 28: \mathrm{E} 506-10$.

25. Minor ME, Morrissey N.J, Peress R, Carroceio A, Ellozy S, Agarwal G, et al. Endovascular treatment of an iatrogenic thoracic aortic injury after spinal instrumentation: case report. J Vasc Surg 2004;39:893-6.

26. Kasten M, Kambach B. Proximal thoracic pedicle serew complications: Fracture with spinal cord injury. Podium presentation, Scoliosis Research Society 2004 annual meeting, Buenos Aires, Argentina, September 2004.

27. Zindrick MR, Wiltse LL, Widell EH, Thomas JC, Holland WR, Field BT, et al. A biomechanical study of intrapeduncular screw fixation in the lumbosacral spine. Clin Orthop 1986;203:99-112.

28. Panjabi MM, Takata K, Goel V, Federico D, Oxland T, Duranceau J, et al. Thoracic human vertebrae. Quantitative three-dimensional anatomy. Spine 1991;16:888901.

29. Hou S, Hu R, Shi Y. Pedicle morphology of the lower thoracic and lumbar spine in a Chinese population. Spine 1993;18:1850-5.

30. Kothe R, O'Holleran JD, Liu W, Panjabi MM. Internal architecture of the thoracic pedicle. An anatomic study. Spine 1996;21:264-70.

31. Hou S, Hu R, Shi Y. Pedicle morphology of the lower thoracic and lumbar spine in a Chinese population. Spine 1993;18:1850-5.

32. Panjabi MM, O'Holleran JD, Criseo JJ $3^{\text {rld }}$, Kothe R. Complexity of the thoracic spine pedicle anatomy. Eur Spine J 1997;6:19-24.

33. Ebraheim NA, Xu R, Ahmad M, Yeasting RA. Projection of the thoracic pedicle and its morphometric analysis. Spine 1997;22:233-8.

34. Ebraheim NA, Jabaly G, Xu R, Yeasting RA. Anatomic relations of the thoracic pedicle to the adjacent neural structures. Spine 1997;22:1553-7.

35. Ebraheim NA, Xu R, Darwich M, Yeasting RA. Anatomic relations between the lumbar pedicle and the adjacent neural structures. Spine 1997;22:2338-41.

36. Hirano T, Hasegawa K, Takahashi HE, Uchiyama S, Hara T, Washio T, et al. Structural characteristics of the pedicle and its role in screw stability. Spine 1997;22:2504-9; discussion 10.

37. Liljenqvist UR, Link TM, Halm HF. Morphometric analysis of thoracie and lumbar vertebrae in idiopathic scoliosis. Spine 2000;25:1247-53.

38. Zindrick MR, Knight GW, Sartori M.J, Carnevale T.J, Patwardhan AG, Lorenz MA. Pedicle morphology of the immature thoracolumbar spine. Spine 2000;25:272635 .

39. McLain RF, Ferrara L, Kabins M. Pedicle morphometry in the upper thoracic spine: limits to safe screw placement in older patients. Spine 2002;27:2467-71.

40. Parent S, Labelle H, Skalli W, de Guise J. Thoracic pedicle morphometry in vertebrae from scoliotic spines. Spine 2004;29:239-48.

41. Tan SH, Teo EC, Chua HC. Quantitative three-dimensional anatomy of cervical, thoracic and lumbar vertebrae of Chinese Singaporeans. Eur Spine J 2004;13:13746.

42. Datir SP, Mitra SR. Morphometric study of the thoracic vertebral pedicle in an Indian population. Spine 2004;29:1174-81

43. Sjostrom L, Jacobsson O, Karlstrom G, Pech P, Rauschning W. CT analysis of pedicles and screw tracts after implant removal in thoracolumbar fractures. J Spinal Disord 1993;6:225-31.

44. Rinella AS, Cahill P, Ghanayem A, et al. Thoracic pedicle expansion after pedicle screw placement in a pediatric cadaveric spine. Podium presentation, Scoliosis Research Society 2004 annual meeting, Buenos Aires: Argentina; September 2004.

45. Polly DW Jr, Potter BK, Kuklo TR, Young S, Johnson C, Klemme WR. Volumetric spinal canal intrusion: a comparison between thoracic pedicle screws and thoracic hooks. Spine 2004;29:63-9.

46. Kim YJ, Lenke LG, Cheh G, Riew KD. CT scan accuracy of "Free Hand" pedicle screw placement technique in spinal deformity: An analysis of 789 pedicle screws, Podium presentation, International Meeting on Advanced Spine Technology Annual Meeting: Bermuda; July 1-3, 2004.

47. Kim Y.J, Lenke LG, Cho YS, Kim CH. Determination of reliable anatomical landmarks in a rotated spine using plain radiographs: A radiographic study of 5 cadavers to define the midvertebral body line, Scoliosis Research Society 2005 Annual meeting (Submitted). 
48. Roy-Camille RR, Saillant G, Mazel C. Internal fixation of the lumbar spine with pedicle serew plating. Clin Orthop 1986;203:7-12

49. Vaccaro AR, Rizzolo S.J, Balderston RA, Allardyce T.J, Garfin SR, Dolinskas C, et al. Placement of pedicle screws in the thoracic spine. Part II: An anatomical and radiographic assessment. J Bone Joint Surg Am 1995; 77:1200-6.

50. Kim YJ, Lenke LG, Bridwell KH, Cho YS, Riew KD. Free hand pedicle screw placement in the thoracic spine:Is it safe? SRS Specialty Issue, Spine 2004;29:333-42.

51. Lehman RA Jr, Polly DW Jr, Kuklo TR, Cunningham B, Kirk KL, Belmont PJ Jr: Straight-forward versus anatomic trajectory technique of thoracic pedicle screw fixation: A biomechanical analysis. Spine 2003;28:2058-65.

52. George DC, Krag MH, Johnson CC, Van Hal ME, Haugh LD, Grobler LJ. Hole preparation techniques for transpedicular screws. Effect on pull-out strength from human cadaveric vertebrae. Spine 1991;16:181-4.

53. Kuklo TR, Lehman RA Jr. Effect of various tapping diameters on insertion of thoracic pedicle screws:a biomechanical analysis. Spine 2003;28:2066-71.

54. Kuklo TR, Potter B, Polly DW Jr, Lenke LG. Corrective capacity of monoaxial versus Multiaxial thoracic pedicle screw in adolescent idiopathic scoliosis. Podium presentation, Scoliosis Research Society 2004 annual meeting, Buenos Aires, Argentina, September 2004

55. Lehman RA, Potter BK, Kuklo TR, Chang AS, Polly DW Jr, Shawen SB, et al. Probing for thoracic pedicle screw tract violation(s):is it valid? J Spinal Disord Tech $2004 ; 17: 277-83$

56. Kim YJ, Lenke LG, Cheh G, Riew D. Evaluation of pedicle screw placement in the deformed spine using intraoperative plain radiographs: A comparison with $\mathrm{CT}$ scans. Spins, SRS Specialty Issue 2005 (Accepted).

57. Lewis S.J, Lenke LG, Raynor BL, Long J, Bridwell KH, Padberg AM. Triggered electromyographic threshold for accuracy of thoracic pedicle screw placement in a porcine model. Spine $2001 ; 26: 2485-9$.
58. Raynor BL, Lenke LG, Kim Y.J, Hanson DS, Wilson-Holden T.J, Bridwell KH, et al. Can triggered EMG thresholds accurately predict Thoracic pedicle screw placement? Spine $2002 ; 27: 2030-5$.

59. Danesh-Clough T, Taylor P, Hodgson, Walton M. The use of evoked EMG in detecting misplaced thoracolumbar pedicle screws. Spine 2001;26:1313-6.

60. Reidy DP, Houlden D, Nolan PC, Kim M, Finkelstein JA. Evaluation of electromyographic monitoring during insertion of thoracic pedicle screws. J Bone Joint Surg Br 2001;83:1009-14.

61. Kim YJ, Padberg AM, Lenke LG, Riew KD. Reliability of In-Vivo Triggered EMGs Thresholds in detecting medial malposition of pedicle screws: Comparison between the thoracic and lumbar Spine, Poster presentation by International Meeting on Advanced Spine Technology Annual meeting: Bermuda; July 1-3, 2004.

62. Lehman RA Jr, Kuklo TR. Use of the anatomic trajectory for thoracic pedicle screw salvage after failure/violation using the straight-forward technique: A biomechanical analysis. Spine 2003;28:2072-7.

63. Kim YJ, Lenke LG, Cheh G, Riew KD. Defining the learning curve of free hand pedicle screw placement for adolescent idiopathic scoliosis surgery: Sixty-seven consecutive cases. Poster presentation International Meeting on Advanced Spine Technology Annual Meeting: Bermuda; July 1-3, 2004.

64. Gertzbein SD, Robbins SE. Accuracy of pedicular screw placement in vivo. Spine 1990;15:11-4.

65. Belmont PJ, Klemme WR, Dhawan A, Polly DW Jr. In vivo accuracy of thoracic pedicle screws. Spine 2001;26:2340-6.

66. Youkilis AS, Quint DJ, MeGillicuddy JE, Papadopoulos SM. Stereotactic navigation for placement of pedicle screws in the thoracic spine. Neurosurgery 2001;48:771-9.

67. Gayet LE, Pries P, Hamcha H, Clarac JP, Texereau J. Biomechanical study and digital modeling of traction resistance in posterior thoracic implants. Spine $2002 ; 27: 707-14$.

\section{Forthcoming Events}

\begin{tabular}{|c|c|}
\hline $\begin{array}{l}\text { EVENT } \\
\text { DATE, } \\
\text { VENUE } \\
\text { CONTACT }\end{array}$ & $\begin{array}{l}\text { 6th Annual National Conference of Neurospinal Surgeons Foundation of India } \\
\text { 28th - 30th September 2006, Jaipur, Rajasthan } \\
\text { Dr. R. S. Mittal Secretariat } \\
\text { Prof, Neuro-Surgery, 2/1, Heera Bagh Flats, Sawai Ram Singh Road, Jaipur, Rajasthan, India, } \\
\text { Tel.: 91-141-2566484, Fax: 91-141-2571317, Email: dr_mittal@hotmail.com }\end{array}$ \\
\hline $\begin{array}{l}\text { EVENT } \\
\text { DATE, } \\
\text { VENUE } \\
\text { CONTACT }\end{array}$ & $\begin{array}{l}\text { 14th Annual Conference of Indian Academy of Neurology } \\
\text { 6th - 8th October 2006, Convention Center NIMHANS, Bangalore } \\
\text { Secretariat } \\
\text { Department of Neurology HIMHANS, Hosur Road, Bangalore-560 029, Tel.: } 91-8026995150 \text {, } \\
\text { Fax: } 91-80-26564830 \text {, Email: iancon2006@gmail.com }\end{array}$ \\
\hline $\begin{array}{l}\text { EVENT } \\
\text { DATE, } \\
\text { VENUE } \\
\text { CONTACT }\end{array}$ & $\begin{array}{l}\text { 8th Annual Conference of Skull Base Surgery Society of India } \\
\text { 13th - 15th October 2006, Chandigarh, India } \\
\text { Secretariat } \\
\text { Dept. of Neuro Surgery, PGIMER, Chandigarh } 160012 \text { India, } \\
\text { Tel. +91172 2756688, 2748077 Fax: +91172 2748077, Email: drguptasunil@gmail.com }\end{array}$ \\
\hline $\begin{array}{l}\text { EVENT } \\
\text { DATE, } \\
\text { VENUE } \\
\text { CONTACT }\end{array}$ & $\begin{array}{l}\text { The 8th Asian Oceanian International Congress on Skull Base Surgery } \\
\text { 1st - 4th November 2006, Dubai United Arab Emirates } \\
\text { Secretariat } \\
\text { Department of Neurosciences, MBC-76, KFSH \& RC, PO Box 3354, Riyadh 11211, Kingdom of Saudi Arabia, } \\
\text { Tel.: + } 966.1 .442 .7773 \text {, Fax: }+966.1 .442 .4763 \text {, www.aosbs2006.org }\end{array}$ \\
\hline
\end{tabular}

